\title{
BMJ Open Geographical variation and urban-rural disparity of overweight and obesity in Chinese school-aged children between 2010 and 2014: two successive national cross-sectional surveys
}

\author{
Yanhui Dong, ${ }^{1}$ Yinghua Ma, ${ }^{1}$ Bin Dong, ${ }^{1}$ Zhiyong Zou, ${ }^{1}$ Peijin Hu, ${ }^{1}$ Zhenghe Wang, ${ }^{1}$ \\ Yide Yang, ${ }^{2}$ Yi Song, ${ }^{1}$ Jun $\mathrm{Ma}^{\oplus} 1$
}

To cite: Dong Y, Ma Y, Dong B, et al. Geographical variation and urban-rural disparity of overweight and obesity in Chinese school-aged children between 2010 and 2014: two successive national crosssectional surveys. BMJ Open 2019;9:e025559. doi:10.1136/ bmjopen-2018-025559

- Prepublication history and additional material for this paper are available online. To view these files, please visit the journal online (http://dx.doi org/10.1136/bmjopen-2018025559).

Received 24 July 2018 Revised 16 February 2019 Accepted 18 February 2019

Check for updates

(c) Author(s) (or their employer(s)) 2019. Re-use permitted under CC BY-NC. No commercial re-use. See rights and permissions. Published by BMJ.

${ }^{1}$ Institute of Child and Adolescent Health, School of Public Health, Peking University, Beijing, China

${ }^{2}$ School of Medicine, Hunan Normal University, Changsha, China

\section{Correspondence to}

Professor Jun Ma;

majunt@bjmu.edu.cn and Dr Yi

Song;

songyi@bjmu.edu.cn

\section{ABSTRACT}

Purpose The urban-rural disparity for childhood overweight and obesity shows different patterns in most countries. This study aimed to examine the recent trend of urban-rural disparity for childhood overweight and obesity at national and subnational levels in Chinese children from 2010 to 2014.

Design Two successive national cross-sectional studies. Overweight and obesity were classified using Chinese national age-specific and sex-specific body mass index reference. The prevalence of overweight and obesity was compared between urban and rural areas at national and subnational levels.

Setting Thirty-one provinces in China.

Participants Data were obtained from the Chinese National Survey on Students' Constitution and Health in 2010 and 2014 with 215214 (107 741 in 2010 and 107473 in 2014) children aged 7-12 years.

Results The overweight and obesity prevalence increased from $17.1 \%$ in 2010 to $22.5 \%$ in 2014 . The overweight and obesity prevalence in both urban and rural areas was higher in the eastern provinces but lower in the western provinces. The urban-rural disparity in overweight and obesity decreased steadily from 2010 to 2014 (1.79 to 1.42 for prevalence $0 \mathrm{R})$. There was greater urban-rural disparity in western China than eastern China. A reversal occurred in 2014 in several eastern provinces where the overweight and obesity prevalence in rural children surpassed that of their urban peers.

Conclusions A narrowing urban-rural disparity and the reversal signal between urban and rural areas in overweight and obesity would contribute to a growing proportion of obese children in rural areas. Therefore, urgent region-specific policies and interventions with a forward-looking approach should be considered for Chinese children, especially in rural areas.

\section{INTRODUCTION}

The persisting epidemic of childhood obesity is a serious public concern that requires urgent attention. ${ }^{1}$ Childhood overweight or obesity is associated with adverse health
Strengths and limitations of this study

- Subnational studies of overweight and obesity aiming at the pattern of urban-rural disparity among Chinese children, with two successive national surveys from 2010 to 2014, were investigated.

- The new evidence of a reversal of urban-rural disparity reported that the prevalence of overweight and obesity in rural children surpassed that of their urban peers in several provinces with high economic levels.

- Geographical changes were used to analyse the urban-rural disparity and its different pace of the childhood obesity epidemic, which supported the similar pattern of the obesity epidemic and the reversal phenomenon in the western provinces with low economic levels following the eastern provinces with higher economic status in the future.

- Data on factors influencing the geographical and urban-rural disparities for childhood overweight and obesity were lacking.

consequences such as dyslipidaemias, type II diabetes, obstructive sleep apnoea and left ventricular hypertrophy, throughout the course of life. ${ }^{2}{ }^{3}$ Childhood obesity also presents with adverse psychosocial consequences and low educational attainment. ${ }^{45}$ Globally, the prevalence of obesity has increased substantially, and China is no exception. ${ }^{67}$

Huge geographical and urban-rural disparities in childhood overweight and obesity occurred across the world. Recent data has shown that global age-standardised prevalence of obesity substantially increased from $0.7 \%$ in 1975 to $5.6 \%$ in 2016 in girls, and from $0.9 \%$ in 1975 to $7.8 \%$ in 2016 in boys, and it has also suggested a large regional difference across the world that a plateaued or even a decreased trend in childhood overweight and obesity occurred in many high-income 
countries at high levels, such as western Europe and the high-income English-speaking and Asia-Pacific regions, and central and Andean Latin America, but an accelerated trend occurred in the east and south Asia. ${ }^{2}$ For example, the ever-increasing trends for obesity occurred in China during the past three decades from $0.1 \%$ in 1985 to $5.0 \%$ in $2010 .{ }^{8}$ Urban-rural disparities were also seen in different trends across the world. Unlike the developed countries such as USA, ${ }^{9}$ Sweden ${ }^{10}$ and Japan, ${ }^{11}$ where the prevalence of childhood obesity is higher in rural areas, China is facing the development of urban-rural disparity, where childhood obesity is higher in urban areas with high socioeconomic status (SES), ${ }^{12}$ but the gap is decreasing. ${ }^{8}$

However, the subnational geographical variation and the changes in urban-rural disparity in childhood overweight and obesity in China in recent years still remain unknown. Analysing the geographical distribution and recognising the changes for childhood overweight and obesity over time may help to identify geographical variation in at-risk groups and provide a reference for other countries, especially low-income and middle-income countries (LMICs) undergoing rapid socioeconomic development. To date, no subnational studies of overweight and obesity aiming at urban-rural disparity among Chinese children have been reported.

A previous study found that the highest prevalence of overweight and obesity occurred in Chinese children aged 7-12 years before puberty. ${ }^{13}$ In addition, because of the policy of compulsory 9 years education in China, children aged 7-12 years are in the primary education stage, whose overweight status is more amenable to policy intervention in practice. ${ }^{1415}$ This study used the data in 2010 and 2014 from the Chinese National Survey on Students' Constitution and Health (CNSSCH), which were two successive nationally representative cross-sectional surveys. The objectives of our study were (1) To assess the recent trend in overweight and obesity among Chinese children aged 7-12 years. (2) To assess the change in the pace of urban-rural disparity from 2010 to 2014. (3) To estimate the prevalence of subnational geographical variation of overweight and obesity with regards to urbanrural disparity during that period.

\section{METHODS}

\section{Study design}

We obtained data from the 2010 and 2014 CNSSCH, which is the largest nationally representative survey of schoolaged children designed to investigate their health status in China. The sampling procedures of $\mathrm{CNSSCH}$ have been published previously in detail. ${ }^{16}$ The procedures of CNSSCH between 2010 and 2014 remained consistent. Data were from 31 mainland provinces excluding Hong Kong, Macao and Taiwan. In each province, the participants were selected by multistage, stratified, random cluster sampling; sampling yielded equal numbers at three SES groups (prefecture-level cities) (ie, upper, moderate, low) within each province defined based on five SES indicators including regional gross domestic product, total yearly income per capita, average food consumption per capita, natural growth rate of the population and the regional social welfare index. All the prefecture-level cities within each province were ranked according to different SES indicators separately and were divided into three categories. In each category, one prefecture-level city was randomly selected among cities with the same grade of five SES indicators. In the present study, children aged 7-12 years in primary schools were selected randomly in each province and sampling took place in classes selected randomly from each grade in the selected schools. This procedure was used to select both the urban and rural schools, except those in Tibet where only urban Tibetan children in Lhasa were surveyed for feasibility reasons.

\section{Participants' involvement and data collection}

In this study, participants were involved if they and their parents had lived in the local areas for longer than 1 year. All eligible participants in our study underwent a complete medical examination before data collection. All the data on height and weight of participants in the selected survey sites were obtained from the anthropometrical measurements after obtaining informed consent and medical examination. Of 215789 participants, 575 participants with missing data were excluded. Thus, our sample size for analysis was 215214.

\section{Measures and definition}

Anthropometrical measurements were conducted by welltrained health workers who passed a training course in anthropometrical measurements and followed a reference protocol recommended by the 2006 WHO Child Growth Standards. ${ }^{17}$ Height $(\mathrm{cm})$ and weight $(\mathrm{kg})$ were measured to the nearest $0.1 \mathrm{~cm}$ and $0.1 \mathrm{~kg}$ with a portable wall-mounted stadiometer and standardised scale using the mean values of three measurements. All children were required to wear only light clothing and stand erect, barefoot and at ease while being measured. Both the stadiometers and scales were calibrated before use and similar instruments were used in measurement at all survey sites.

Body mass index (BMI) was calculated as body weight $(\mathrm{kg})$ divided by height $(\mathrm{m})$ squared $\left(\mathrm{kg} / \mathrm{m}^{2}\right)$. The definition of overweight and obesity used the national definitions from the Working Group on Obesity in China,${ }^{18}$ and it was a kind of an age-specific and sex-specific BMI reference standard of Chinese children. Overweight was defined as BMI $>85$ th centile but $\leq 95$ th centile, relative to gender and age, whereas obesity was defined as BMI $>95$ th centile. This standard is one of the most broadly used one in China that showed its superiority in both prospectivity and actuality, and is consistent with the east Asian ethnic characteristics of body fatness growth, which could eliminate the influence of different populations with different growth patterns and fat accumulation. ${ }^{19}$ We also conducted a sensitivity analysis using the WHO definitions. ${ }^{20} \mathrm{BMI} \mathrm{Z}$ scores were calculated as the child's BMI minus the median BMI, and divided by the SD for that child's age and sex in the WHO reference 
population. BMI Z scores of more than 1 and 2 were classified as overweight and obesity, respectively. Thirty-one mainland provinces were analysed in our study, and they were divided into three regions: the east region, the central region and the west region according to the geographical standard division from the National Bureau of Statistics of China (online supplementary figure S1). ${ }^{21}$ Informed consent was obtained from both children and their parents.

\section{Statistical analysis}

The present study calculated the crude prevalence of overweight and obesity based on the original data set to assess the nutritional status of children. Anthropometrical and categorical variables were compared using $\chi^{2}$ and t tests between the 2010 and 2014 survey years. The geographical distributions of overweight and obesity at subnational levels were compared (excluding Hong Kong, Macau and Taiwan) using the Spmap module in Stata. The prevalence of overweight and obesity, and its changes between 2010 and 2014 in each province was presented using descriptive statistics. To assess urban-rural disparities in these two survey years, we used logistic regression to estimate the prevalence ORs (PORs) for overweight and obesity in urban versus rural areas with adjustment for province and subnational SES indicator. The same calculation of PORs was also conducted in the east, central and west regions of China. All analyses were conducted using both national definitions and WHO definitions, and the WHO definitions were used for sensitivity analysis. All analyses were performed using Stata V.12.0 software. Two-sided p values $<0.05$ were considered statistically significant.

\section{RESULTS}

\section{The characteristic of the study sample}

As shown in online supplementary table S1, the distribution for sex, age and urban/rural children between the two survey years were quite similar. The average height, weight and BMI increased from 2010 to 2014 and the prevalence of overweight and obesity increased from $17.1 \%$ in 2010 to $22.5 \%$ in 2014 using national definitions (from $22.5 \%$ in 2010 to $28.6 \%$ in 2014 using the WHO definitions).
Urban-rural disparity in overweight and obesity by age groups The prevalence of overweight and obesity was stable across the age bands from ages from 7 years to 12 years in both 2010 and 2014, and increased evenly in each age from 2010 to 2014 (figure 1). The prevalence of overweight and obesity in urban children was higher than their rural peers, and the same ever-increasing trends occurred in each age of both urban and rural areas. However, the increase in the prevalence of overweight and obesity was higher in rural areas than in urban areas of corresponding age (online supplementary figure S2 and online supplementary tables S2 and S3).

\section{Trends in the prevalence of overweight and obesity at the subnational level}

Figure 2 shows that in both 2010 and 2014, the provinces with high prevalence of overweight and obesity were mainly concentrated in the eastern regions, particularly in the Circum-Bohai Sea Regions (including Shandong, Beijing, Tianjin, Hebei and Liaoning provinces). From 2010 to 2014, most of the provinces showed greater increases in overweight and obesity, with Shaanxi province especially showing the largest increment (11.6 percentage points) while Hainan showed the lowest increment (5.3 percentage points, online supplementary tables S4 and S5). Sensitivity analysis using the WHO definitions presented the same epidemic characteristics (online supplementary figure S3).

\section{Trends in urban-rural disparity for overweight and obesity at the subnational level}

Figure 3 shows the further analysis of subnational distribution and trends for the prevalence of overweight and obesity in urban and rural areas. Compared with rural areas, there were more provinces with higher prevalence of overweight and obesity in urban areas, especially in the north, north-east and Circum-Bohai Sea Regions. For example, the prevalence of overweight and obesity in urban and rural areas were $38.2 \%$ and $32.6 \%$, respectively, in Tianjin, which ranked the top one and the top three in 2014 in all the 31 provinces. However, more rural areas showed greater increase in overweight and obesity than urban areas at the subnational level. Similar

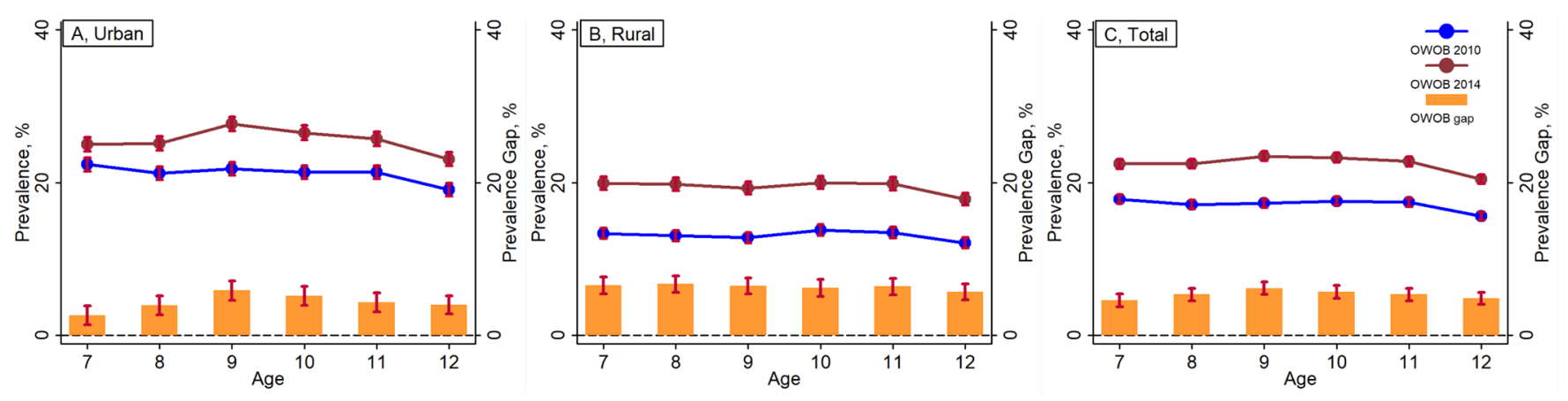

Figure 1 Comparison of overweight and obesity between 2010 and 2014 with age from 7 years to 12 years in different subgroups. OW\&OB, overweight and obesity; A, urban; B, rural; C, total. 


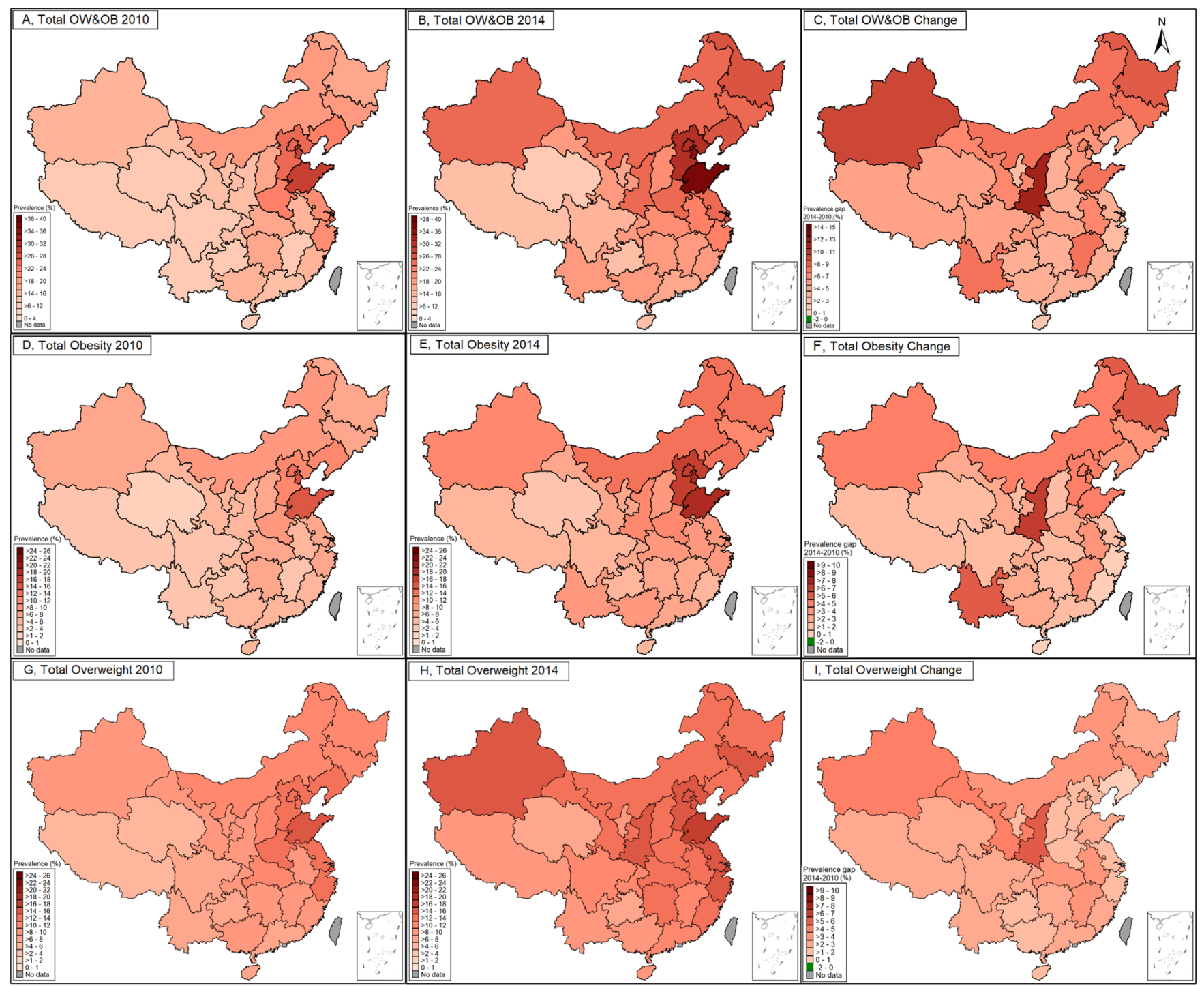

Figure 2 The distribution and changes in the prevalence of overweight and obesity in 31 national provinces between 2010 and 2014. A and B, total overweight and obesity in 2010 and 2014, respectively; D and E, obesity in 2010 and 2014 , respectively; G and $\mathrm{H}$, overweight in 2010 and 2014, respectively; C, changes in total overweight and obesity between 2010 and 2014 , obesity only (F) and overweight only (I) separately. OW\&OB, overweight and obesity.

changes of urban-rural disparity at subnational levels were observed for overweight and obesity prevalence separately, even using the WHO definitions for sensitivity analysis (online supplementary figures S4-S8). When stratified by urban-rural areas, Shanxi, Henan and Shanghai presented decreased trends for overweight and obesity among urban children during this period, and this decline was also seen in rural children in Zhejiang (online supplementary tables S4 and S5).

Figure 4 also shows the gap between urban and rural areas in 2010 and 2014. Most provinces presented a large urban-rural disparity in overweight and obesity with higher prevalence in urban areas than rural areas, but a reversal phenomenon with higher prevalence in rural areas than urban areas occurred in some provinces in the eastern regions, such as Beijing, Shandong and Zhejiang. For example, Shandong and Zhejiang provinces showed a reversal phenomenon in obesity in rural children simultaneously in 2010, and the trends continued till 2014 adding two additional provinces (Beijing and Yunnan, online supplementary table S6), even using the WHO definitions (online supplementary figure S9). Further sex-stratified analyses presented the same reversal epidemiological transition between urban and rural areas for overweight and obesity in both boys and girls from 2010 to 2014 using both national and WHO definitions (online supplementary figures S10-S12).

\section{PORs of urban versus rural children for overweight and obesity}

Table 1 shows that the PORs of urban versus rural children for overweight and obesity decreased from 2010 to 2014. A same decrease in PORs was also observed in the eastern, central and western regions, and the increase in 


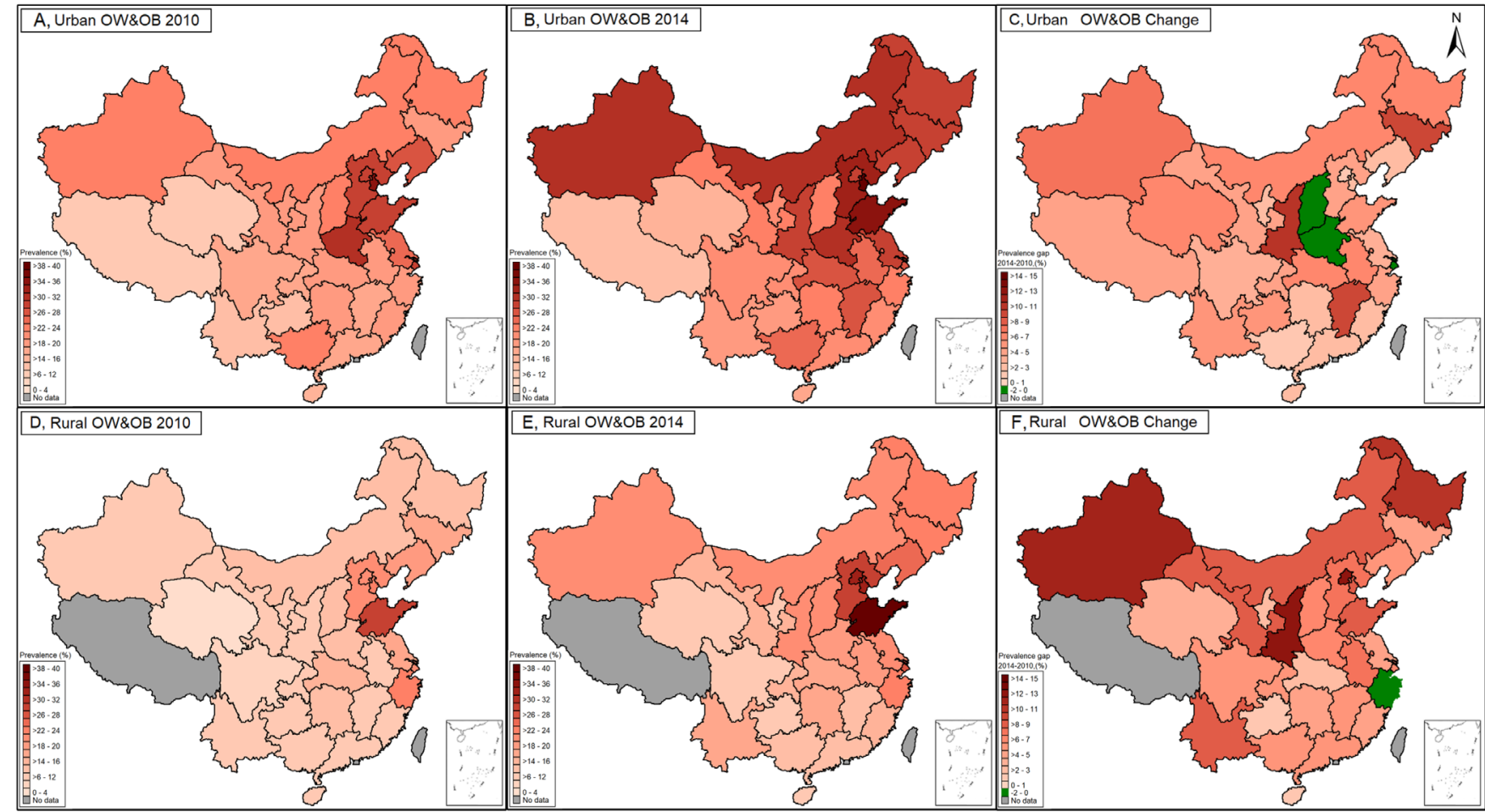

Figure 3 The distribution and changes for prevalence of overweight and obesity in different subgroups in 31 national provinces between 2010 and 2014. A and B, total overweight and obesity in urban areas in 2010 and 2014, respectively; D and E, total overweight and obesity in rural areas 2010 and 2014, respectively; C and F, changes for overweight and obesity in urban and rural areas between 2010 and 2014, respectively. OW\&OB, overweight and obesity.

PORs that was seen as a gradient from the east to west geographically suggests a larger urban-rural disparity in west compared with east China. For example, the PORs of urban versus rural children in overweight and obesity in the eastern, central and western regions were $1.20(95 \%$ CI 1.14 to 1.25 ), 1.56 (95\% CI 1.47 to 1.65 ) and 1.70 (95\% CI 1.61 to 1.79), respectively, which showed ever-increasing trends and were lower than the corresponding regional prevalence in 2010 (1.49 (95\% CI 1.42 to 1.57 ), 1.87 (95\% CI 1.75 to 1.99 ) and 2.46 (95\% CI 2.31 to 2.62)). Sex-stratified analyses showed the same trends in boys and girls even for the sensitivity analysis using the WHO definitions (online supplementary table S7). Notably, the urban-rural disparity for overweight and obesity in girls was lower than that in boys in the same period and region. Until 2014, the urban-rural disparity for obesity was not statistically significant among girls of eastern regions (POR $0.96(0.87,1.06))$.

\section{DISCUSSION}

The pattern and timing of urban-rural disparity for childhood overweight and obesity appear different between developed and developing countries, but there's little doubt that the majority of countries in the world are experiencing the narrowing trends in urban-rural disparity, including China. ${ }^{82}$ Previous studies have shown that urban children had a higher prevalence of overweight and obesity than their rural counterparts who had faster increased pace. ${ }^{2324}$ The present study showed that the urban-rural disparity in overweight and obesity continued to narrow from 2010 to 2014 at the national level. There was new evidence of a reversal in urban-rural disparity with the prevalence of overweight and obesity in rural children surpassing that of their urban peers in several provinces with high economic levels. As far as we know, this is the first study to analyse the urban-rural disparity in excess body weight at subnational levels and report the reversal phenomenon in Chinese children.

The ongoing epidemiological and nutritional transition in the world offer an important potential explanation. Compared with urban children in high-income countries, rural children had higher risks of overweight status due to the higher accessibility of high-calorie diets and sugary drinks which were the more economically affordable option in countries such as USA, ${ }^{9}{ }^{25}$ Britain $^{26}$ and Australia. ${ }^{27}$ But LMICs have not yet reached the same phase of nutritional transition as the economically affluent countries, and such diets are still reserved for urban children in some countries, such as India, Brazil and China, where economic growth has only just begun to allow affluent individuals to afford fast food. ${ }^{28-31}$ However, China, with rapid but uneven economic development, is shifting towards the model of high-income countries. Some provinces with high economic status have taken the lead in reversal of urban-rural disparities in childhood overweight status in the context of epidemiological 


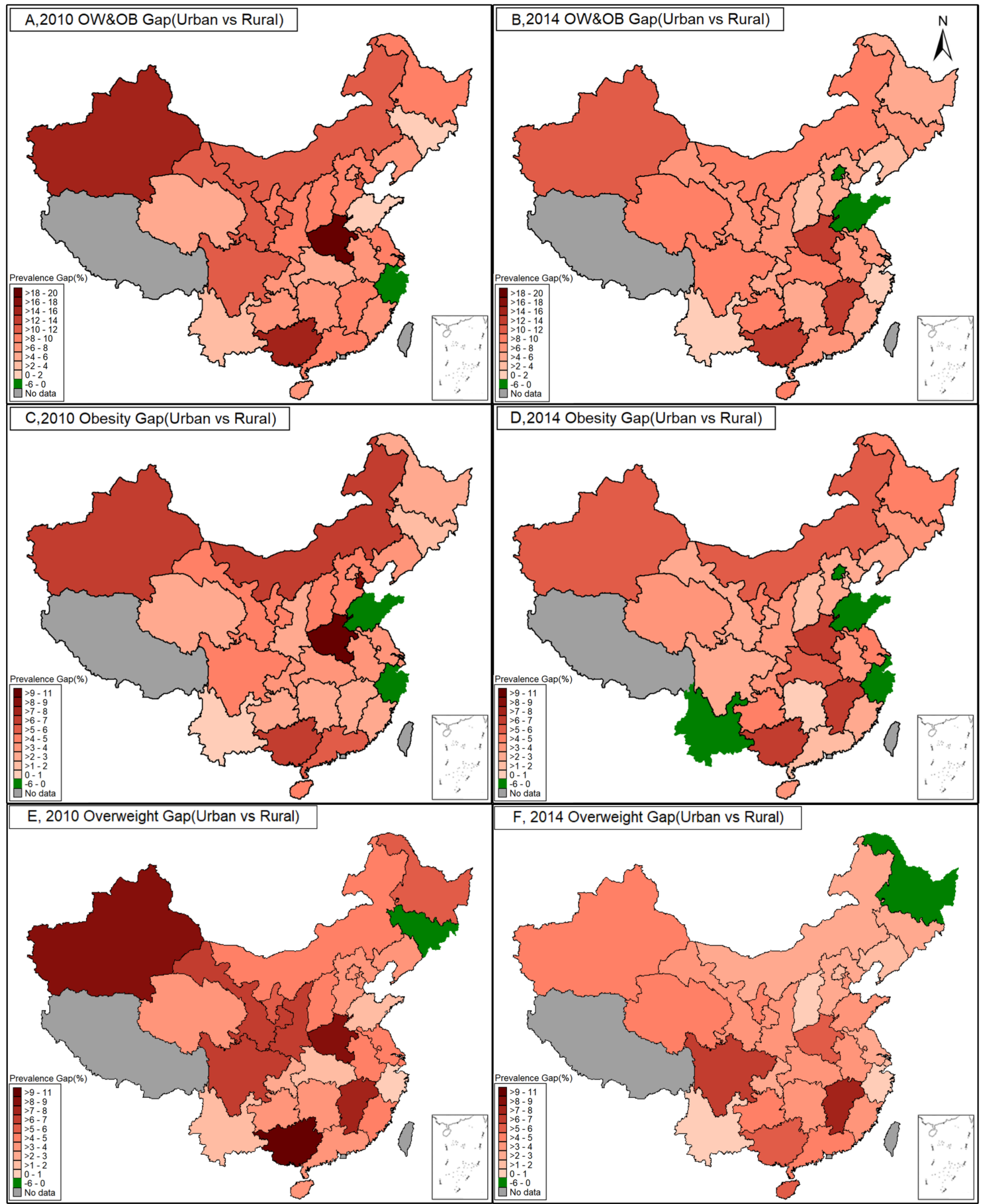

Figure 4 The changes in prevalence gaps of overweight and obesity between rural and urban areas in 31 national provinces between 2010 and 2014. A and B, prevalence gap for overweight and obesity between urban and rural areas in 2010 and 2014, respectively; C and D, prevalence gap for obesity between urban and rural areas in 2010 and 2014, respectively; E and F, prevalence gap for overweight between urban and rural areas in 2010 and 2014, respectively. OW\&OB, overweight and obesity. 


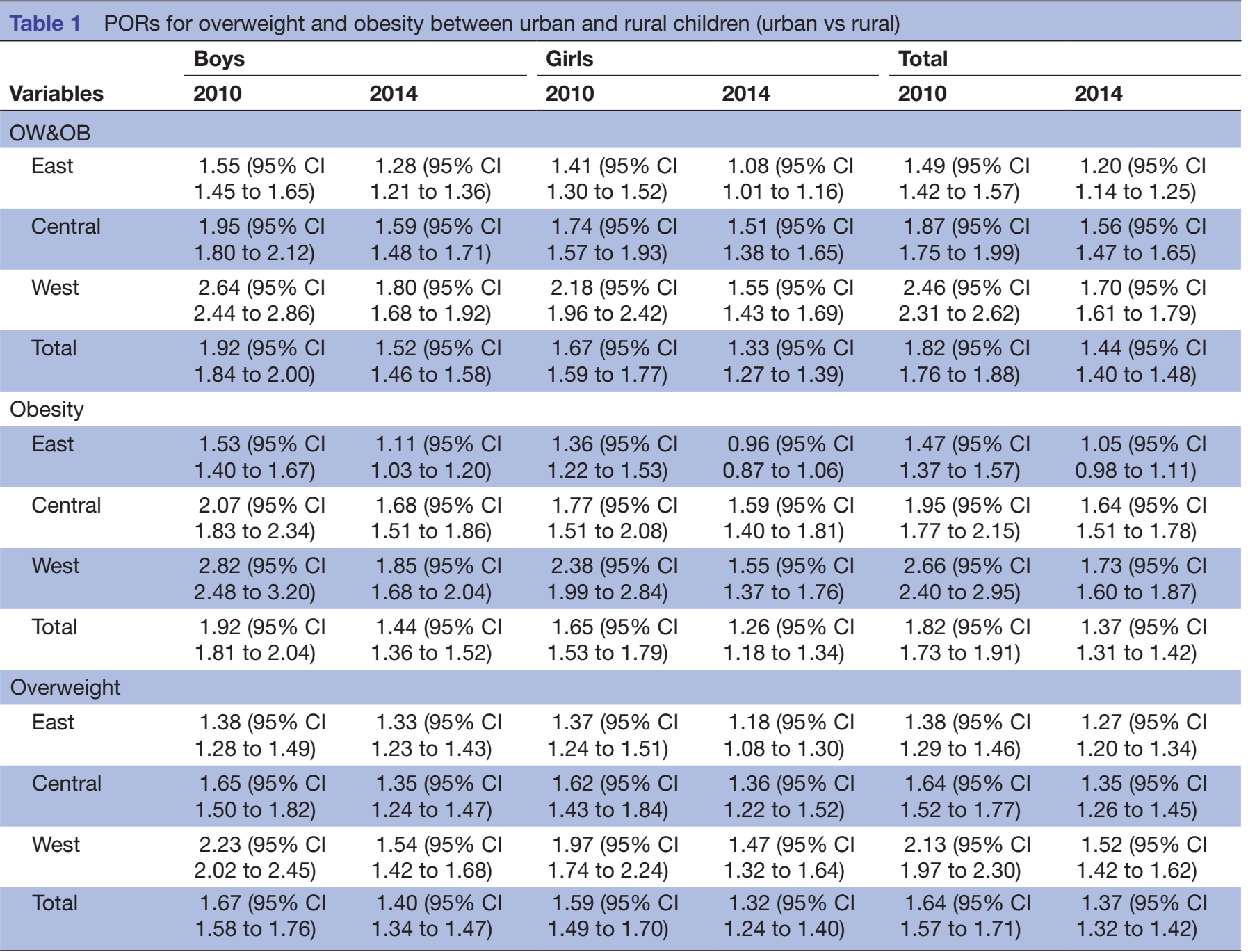

Adjusted for province and socioeconomic status.

OW\&OB, overweight and obesity using the national definitions; PORs, prevalence ORs.

and nutritional transition, such as Beijing, Zhejiang and Shandong, whose per capita GDP ranked the top 2, 5 and 10 , respectively, in all of the 31 provinces. ${ }^{32} \mathrm{~A}$ specific example in this context is UK where socioeconomic inequalities in weight have reversed from 1953 to 2015 so that low socioeconomic position is now linked to higher rates of overweight/obesity in children. ${ }^{26}$ Thus, the rapid shift and the reversal phenomenon suggest that after a time lag, children in rural areas of LMICs or some undeveloped areas in a country may have higher risks of developing overweight/obesity in future.

In the context of this epidemiological and nutritional transition, it is important to recognise the Chinese specific potential reasons for the narrowing urban-rural disparity in overweight and obesity in children. First, sustainable economic growth in China has been widely considered an effective instrument for improving nutritional status in children, ${ }^{33}$ because economic growth can increase family income, which allows households to spend more on enhancing the nutritional status of children. Second, customised implementation of the nutrition improvement programme was sustainably conducted in the developing areas of China. For example, the nutritional policies of 'the standard amount of nutritional supply for a student's lunch' (1998), ${ }^{34}$ 'nutrition improvement programme among rural compulsory education students' (2011), ${ }^{35}$ 'free compulsory education in rural areas' $(2006)^{36}$ issued by the Chinese government might be the key for improving children's nutritional status and promoting the narrowing urban-rural disparity. Third, the gaps of living standards between urban and rural residents narrowed during the decades, which was supported by the changes of Engel coefficients. Engel coefficients, the proportion of family income spent on food and a indicator indicating the living standard of people ${ }^{37}$ were $35.7 \%$ and $41.1 \%$ in 2010 for urban and rural residents , respectively, but narrowed further to $35.2 \%$ and $34.3 \%$ in 2014, respectively. ${ }^{38}$ Fourth, environmental factors and diet changes might play a critical role. A nearly 10-year follow-up study in China found that the structure of the Chinese diet shifted away from high carbohydrate food towards high fat, high energy-density food as income 
improved, particularly in the low-income and middle-income groups. ${ }^{39}$ In addition, the China Health and Nutrition Survey in 2011 found that the urban-rural disparity for the total energy intake, and the consumption of meat and meat products was not significant. ${ }^{40}$ The convergence of diets between urban and rural areas might partly explain the narrowing trend and the reversal in excess body weight.

Our study has some potential implications. First, our study might provide a reference to develop effective prevention policies on the issue of nutritional burden both for domestic regions and other LMICs, because it is reasonable to assume that other corresponding LMICs might face the same narrowing urban-urban disparity trends and the reversal in nutritional problems in the future. Thus, in this context, policy makers and experts should pay attention to rural populations and develop sustainable policies for rural children, even though their obesity prevalence is still lower than that of urban children. Second, comprehensive interventions are needed to prevent obesity so as to alleviate the medical burden in future, such as education on balanced diets and healthy eating habits, diet environment improvement in the society and the encouragement of physical activities. Third, geographical presentation with a nationally representative sample size offered a holistic view of secular nutritional changes in China, which provided the location and direction of priority interventions at present and in the future.

The present study had the following limitations. First, because this study used original data from two cross-sectional surveys, the data can't be used to infer causality, and merely descriptive analyses were adopted in this study. However, the CNSSCH collected nationally representative data with a large sample size, and the prevalence estimated in each CNSSCH could meet our purpose of comparison and geographical analysis. Second, the present study included only Tibetan children in Tibet, and we did not analyse the difference between the two groups. In fact, Tibetan children might not affect our conclusion of urban-rural disparity because we only analysed the urban-rural disparity among Han children due to the lack of rural Tibetan children in the survey, but Tibetan data would increase the data integrity for geographical analysis at national and subnational levels. Third, some influencing factors, for example, dietary behaviour and physical activity in children and maternal or paternal obesity rates, which could further explain the changing trends of childhood obesity, were not collected in this survey.

\section{CONCLUSION}

In summary, the prevalence of overweight and obesity in urban children in China was higher than in rural children, and both of increased steadily from 2010 to 2014 with higher prevalence in the eastern provinces, especially in the north-east and Circum-Bohai Sea Regions, but lower in western provinces, especially in the south-west regions. In the context of the ongoing epidemiological and nutritional transition, China is at a critical juncture in the prevention and control of obesity as seen from the new evidence of the narrowing urban-rural disparity and the reversal in overweight and obesity. Therefore, region-specific policies and interventions with forward-looking consideration are warranted to prevent overweight and obesity in Chinese children, especially in rural areas.

Contributors YD and YS conceptualised and designed the study; YD completed the statistical analyses, drafted the initial manuscript, and reviewed and revised the manuscript; JM and YS designed the study and collected the data; YM, BD, ZZ and $\mathrm{PH}$ assisted with the statistical analyses and critically reviewed and revised the manuscript; ZW and YY assisted with the statistical analyses. All authors were involved in writing the paper and had final approval of the submitted and published versions.

Funding The present study was supported by the National Natural Science Foundation to JM (81673192), and the China Scholarship Council to YD (201806010592).

\section{Competing interests None declared.}

Patient consent for publication Not required.

Ethics approval The surveys were approved by the Medical Research Ethics Committee of the Peking University Health Science CenterCentre (IRB00001052-18002).

Provenance and peer review Not commissioned; externally peer reviewed.

Data sharing statement Some additional data are available in supplementary files and extra data are also available by emailing corresponding author JM or YS.

Open access This is an open access article distributed in accordance with the Creative Commons Attribution Non Commercial (CC BY-NC 4.0) license, which permits others to distribute, remix, adapt, build upon this work non-commercially, and license their derivative works on different terms, provided the original work is properly cited, appropriate credit is given, any changes made indicated, and the use is non-commercial. See: http://creativecommons.org/licenses/by-nc/4.0/.

\section{REFERENCES}

1. Lobstein T, Jackson-Leach R, Moodie ML, et al. Child and adolescent obesity: part of a bigger picture. Lancet 2015;385:2510-20.

2. NCD Risk Factor Collaboration (NCD-RisC). Worldwide trends in body-mass index, underweight, overweight, and obesity from 1975 to 2016: a pooled analysis of 2416 population-based measurement studies in 128.9 million children, adolescents, and adults. Lancet 2017;390:2627-42.

3. Cuspidi C, Rescaldani M, Sala C, et al. Left-ventricular hypertrophy and obesity: a systematic review and meta-analysis of echocardiographic studies. J Hypertens 2014;32:16-25.

4. Caird J, Kavanagh J, O'Mara-Eves A, et al. Does being overweight impede academic attainment? A systematic review. Health Education Journal 2014;73:497-521.

5. Quek YH, Tam WWS, Zhang MWB, et al. Exploring the association between childhood and adolescent obesity and depression: a metaanalysis. Obes Rev 2017;18:742-54.

6. Ng M, Fleming T, Robinson M, et al. Global, regional, and national prevalence of overweight and obesity in children and adults during 1980-2013: a systematic analysis for the Global Burden of Disease Study 2013. Lancet 2014;384:766-81.

7. Song Y, Wang HJ, Ma J, et al. Secular trends of obesity prevalence in urban Chinese children from 1985 to 2010: gender disparity. PLoS One 2013;8:e53069.

8. Song Y, Ma J, Wang HJ, et al. Secular trends of obesity prevalence in Chinese children from 1985 to 2010: Urban-rural disparity. Obesity 2015;23:448-53.

9. Davis AM, Bennett KJ, Befort C, et al. Obesity and related health behaviors among urban and rural children in the United States: data from the National Health And Nutrition Examination Survey 20032004 and 2005-2006. J Pediatr Psychol 2011;36:669. 
10. Sjöberg A, Moraeus L, Yngve A, et al. Overweight and obesity in a representative sample of schoolchildren - exploring the urban-rural gradient in Sweden. Public Health Nutrition 2012;15:1550-1.

11. Matsushita Y, Yoshiike N, Kaneda F, et al. Trends in childhood obesity in Japan over the last 25 years from the national nutrition survey. Obes Res 2004;12:205-14.

12. Chen TJ, Modin B, Ji CY, et al. Regional, socioeconomic and urbanrural disparities in child and adolescent obesity in China: a multilevel analysis. Acta Paediatr 2011;100:1583-9.

13. Wang S, Dong $\mathrm{YH}$, Wang $\mathrm{ZH}$, et al. [Trends in overweight and obesity among Chinese children of 7-18 years old during 1985-2014]. Zhonghua Yu Fang Yi Xue Za Zhi 2017;51:776-80.

14. Amini M, Djazayery A, Majdzadeh R, et al. A School-Based Intervention to Reduce Excess Weight in Overweight and Obese Primary School Students. Biol Res Nurs 2016;18:531-40.

15. Li XH, Lin S, Guo H, et al. Effectiveness of a school-based physical activity intervention on obesity in school children: a nonrandomized controlled trial. BMC Public Health 2014;14:1282.

16. Ji CY, Chen TJ, Working Group on Obesity in China (WGOC). Empirical changes in the prevalence of overweight and obesity among Chinese students from 1985 to 2010 and corresponding preventive strategies. Biomed Environ Sci 2013;26:1-12.

17. World Health Organization. WHO child growth standards: length/ height-for-age, weight-for-age, weight-for-length, weight -for-height and body mass index-for-age: methods and development. http:// www.who.int/childgrowth/standards/Chap_2.pdf?ua=1 (Accessed 25 Apr 2009).

18. Ji CY, Working Group on Obesity in China (WGOC). Report on childhood obesity in China (4) prevalence and trends of overweight and obesity in Chinese urban school-age children and adolescents, 1985-2000. Biomed Environ Sci 2007;20:1-10.

19. Ji CY, Working Group on Obesity in China. Report on childhood obesity in China (1)--body mass index reference for screening overweight and obesity in Chinese school-age children. Biomed Environ Sci 2005;18:390-400.

20. Borghi E, de Onis M, Garza C, et al. Construction of the World Health Organization child growth standards: selection of methods for attained growth curves. Stat Med 2006;25:247-65.

21. National Bureau of Statistics of China. East, west, central and eastnortheast division methods in China. http://www.stats.gov.cn/ztjc/ zthd/sjtjr/dejtjkfr/tjkp/201106/t20110613_71947.htm (Accessed 13 Jun 2011).

22. Jaacks LM, Slining MM, Popkin BM. Recent trends in the prevalence of under- and overweight among adolescent girls in low- and middleincome countries. Pediatr Obes 2015;10:428-35.

23. Song $\mathrm{Y}$, Wang $\mathrm{HJ}$, Dong $\mathrm{B}$, et al. 25-year trends in gender disparity for obesity and overweight by using WHO and IOTF definitions among Chinese school-aged children: a multiple cross-sectional study. BMJ Open 2016;6:e011904.

24. Sun $\mathrm{H}, \mathrm{Ma} Y, \mathrm{Han} D$, et al. Prevalence and trends in obesity among China's children and adolescents, 1985-2010. PLoS One 2014;9:e105469.
25. Johnson JA, Johnson AM. Urban-rural differences in childhood and adolescent obesity in the United States: a systematic review and meta-analysis. Child Obes 2015;11:233-41.

26. Bann D, Johnson W, Li L, et al. Socioeconomic inequalities in childhood and adolescent body-mass index, weight, and height from 1953 to 2015: an analysis of four longitudinal, observational, British birth cohort studies. Lancet Public Health 2018;3:e194-e203.

27. Booth ML, Wake M, Armstrong T, et al. The epidemiology of overweight and obesity among Australian children and adolescents, 1995-97. Aust N Z J Public Health 2001;25:162-8.

28. Youfa WM, Lobstein T. World trends in childhood overweight and obesity. International Journal of Pediatric Obesity 2011:1:11-25

29. Saraswathi YS, Najafi M, Gangadhar MR, et al. Prevalence of childhood obesity in school children from rural and urban areas in Mysore, Karnataka, India. Journal of Life Sciences 2011;3:51-5.

30. Siddiqui ST, Kandala NB, Stranges S. Urbanisation and geographic variation of overweight and obesity in India: a cross-sectional analysis of the Indian Demographic Health Survey 2005-2006. Int J Public Health 2015:60:717-26.

31. Chen M. Evolution and assessment on China's urbanization 19602010: Under-urbanization or over-urbanization? Habitat International 2013;38:25-33.

32. National Bureau of Statistics of China. 3-10 The GDP per capita in each province of China 2014 [Web page]. http://www.stats.gov.cn/ tjsj/ndsj/2015/indexch.htm (Accessed October 31, 2015).

33. McGovern ME, Krishna A, Aguayo VM, et al. A review of the evidence linking child stunting to economic outcomes. Int J Epidemiol 2017;46:1171-91.

34. Ministry of health of China. Amount of nutritional supply for student lunch. http://file4.foodmate.net/foodvip/web/viewer.html?file=./ zengbu/WST100-1998.pdf (Accessed 5 May 1998).

35. Zhang F, Hu X, Tian Z, et al. Literature research of the nutrition improvement programme for rural compulsory education students in China. Public Health Nutr 2015;18:936-43.

36. The Central People's Government of the People's Republic of China. The inform of the State Council on deepening the reform of the security system of funds on rural compulsory education. http://www. gov.cn/zwgk/2006-02/07/content_181267.htm (Accessed 7 Feb 2006).

37. Binnendijk E, Dror DM, Gerelle E, et al. Estimating Willingness-to-Pay for health insurance among rural poor in India by reference to Engel's law. Soc Sci Med 2013;76:67-73.

38. National Bureau of Statistics of China. 6-4 per capita annual income and engel's coefficient of urban and rural households. $2014 \mathrm{http} / / /$ www.stats.gov.cn/tjsj/ndsj/2014/zk/html/Z0604e.htm (Accessed 31 Oct 2015).

39. Du S, Mroz TA, Zhai F, et al. Rapid income growth adversely affects diet quality in China--particularly for the poor!. Soc Sci Med 2004;59:1505-15.

40. Zhang J, Wang D, Eldridge AL, et al. Urban-rural disparities in energy intake and contribution of fat and animal source foods in chinese children aged 4-17 years. Nutrients 2017;9:e526:526. 